\title{
Subtle decline in cardiac mechanics is correlated with albuminuria in asymptomatic normotensive patients with type 2 diabetes mellitus: a two- dimensional strain echocardiography study
}

Sameh Samir Raafat ( $\nabla$ drsnaguib@yahoo.com )

Ainshams University https://orcid.org/0000-0002-7062-0112

Nour Eldin M. Nazmy

Ain Shams University

Islam M. Bastawy

Ain Shams University

Yasser A. Abdellatif

Ain Shams University

Original investigation

Keywords: diabetes mellitus, albuminuria, 2D strain, heart failure, diabetic cardiomyopathy, LV function

Posted Date: June 4th, 2020

DOI: https://doi.org/10.21203/rs.3.rs-30939/v1

License: (c) (i) This work is licensed under a Creative Commons Attribution 4.0 International License.

Read Full License 


\section{Title page}

Subtle decline in cardiac mechanics is correlated with albuminuria in asymptomatic normotensive patients with type 2 diabetes mellitus: a two-dimensional strain echocardiography study

Sameh S. Raafat, $\mathrm{MD}^{1 *}$, Noureldin M. Nazmy, $\mathrm{Msc}^{1}$, Islam M. Bastawy, MD ${ }^{1}$, Yasser A. Abdellatif, MD 1.

Authors' affliation:

${ }^{1}$ Department of Cardiology - Ain Shams University Hospital Abbassya - Cairo - Egypt

*Correspondence:

Dr. Sameh S. Raafat, MD.

Department of Cardiology - Ain Shams University Hospital Abbassya - Cairo - Egypt

Address 36 Ali Irahim Rames street - Heliopolis - Cairo - Egypt P0 11351

Telephone 00201005262711

Fax 20224820416

Email:drsnaguib@yahoo.com 


\section{$\underline{\text { ABSTRACT }}$}

\section{Background:}

Type 2 diabetes mellitus (T2DM) insidiously affects the myocardium with subsequent cardiomyopathy, it also pathologically involves the microvascular bed of the kidney reflected by albuminuria. This study aimed to investigate the relation between albuminuria and subclinical left ventricular (LV) systolic dysfunction in asymptomatic normotensive patients with T2DM assessed by two-dimensional (2D) speckle tracking echocardiography.

\section{Methods and results}

Sixty normotensive patients with T2DM, within 5 years of initial diagnosis, receiving conventional oral antidiabetic medications were included and subdivided into 2 subgroups, each including thirty patients according to the presence of albuminuria, together with thirty healthy control subjects all underwent full echocardiographic examination including left ventricular (LV) regional and global longitudinal strain (GLS) measurements. Laboratory tests including serum creatinine, glycated hemoglobin (HbA1C) and albumin creatinine ratio (ACR) were withdrawn for the three groups. There was a significant reduction in average peak systolic LV global longitudinal strain (GLS) in patients with T2DM when compared to 
control group $(-16.18 \pm 2.78 \%$ versus $-18.13 \pm 2.86 \%, \mathrm{P}<0.001)$, however there was no significant difference in average peak systolic LV GLS between both diabetic subgroups $(-15.57 \pm 2.77 \%$ in subgroup with albuminuria versus $-16.79 \pm 2.70 \%$ in subgroup without albuminuria, $\mathrm{p}=0.077$ ). Moreover, there was a significant correlation between ACR and reduction of GLS in patients with T2DM and albuminuria $(r=0.38$, $\mathrm{P}=0.003$ ). However, this correlation was absent in patients with T2DM without albuminuria $(\mathrm{r}=0.107, \mathrm{P}=0.573)$.

\section{Conclusion:}

Patients with type 2 diabetes mellitus (T2DM) have subclinical LV systolic dysfunction despite normal ejection fraction through reduction of average peak systolic LV GLS that is correlated with albumin creatinine ratio in patients with T2DM and albuminuria.

\section{Keywords:}

diabetes mellitus, albuminuria, 2D strain, heart failure, diabetic cardiomyopathy, LV function 


\section{Manuscript}

\section{$\underline{\text { Text }}$}

\section{Background}

Cardiovascular disease (CVD) is one of the most common comorbidities and causes of death in patients with T2DM. ${ }^{1}$ However, in view of emerging evidence that T2DM represents a stronger predictor of mortality than coronary artery disease (CAD) in cohorts with heart failure, diabetic cardiomyopathy $(\mathrm{DCM})$ is increasingly recognized as a clinically relevant entity. DCM refers to a clinical condition of ventricular dysfunction that occurs in the absence of coronary atherosclerosis and hypertension in patients with diabetes mellitus. ${ }^{2}$ The underlying mechanisms are proposed to be multifactorial yet likely to act synergistically, including microangiopathy, cardiomyocyte hypertrophy, deposition of glycation end products, and myocardial fibrosis with increased myocardial stiffness. ${ }^{3,4}$ It is important to achieve an early diagnosis of DCM in asymptomatic diabetic patients in order to prevent the development of irreversible morphological changes, such as fibrosis, leading to impaired contractility. ${ }^{5}$

Speckle-tracking echocardiography is an imaging technique developed to objectively quantify myocardial function and to analyze cardiac motion and deformation that can unravel the transmural progression of myocardial dysfunction from subclinical stages to the development of heart failure and 
thus provide incremental information beyond the left ventricular ejection fraction (LVEF). ${ }^{6,7}$ Therefore, assessment of peak systolic LV GLS using speckle-tracking imaging may be able to identify subtle changes in cardiac mechanics that are not detectable with conventional echocardiography. ${ }^{8,9}$

Diabetic kidney disease is a life-threatening microvascular complication of T2DM and contributes to both cardiovascular morbidity and mortality. Albuminuria is an independent risk factor of rapid progression of chronic kidney disease (CKD) and is considered a warning sign for CKD in T2DM. The level of urinary albumin excretion has been associated with CVD in patients with T2DM and CKD. In addition, albuminuria is known to be associated with increased LV mass and is theoretically related to multiple pathophysiological processes, including systemic inflammation and endothelial dysfunction. ${ }^{10,11}$

Functioning in tandem, both the heart and kidney are pathologically involved in T2DM. Thus, we speculate that the degree of microvascular involvement in T2DM, reflected by albuminuria and subtle DCM, measured by GLS, might be interrelated.

This study aimed to investigate the relation between albuminuria and subclinical left ventricular (LV) systolic dysfunction in asymptomatic normotensive patients with T2DM assessed by two-dimensional (2D) speckle tracking echocardiography. 


\section{$\underline{\text { Methods }}$}

This study was approved by our institutional review board and informed consent was obtained from all individuals enrolled in the study

\section{Study population:}

This was a prospective observational study conducted in the Cardiology Department Ain Shams University Hospitals including 60 asymptomatic normotensive patients with T2DM, within 5 years of initial diagnosis and receiving conventional oral antidiabetic medications recruited from the outpatient clinic and 30 age and sex matched controls. The sixty patients with T2DM were further subdivided into 30 normotensive patients with T2DM and albuminuria, defined as albumin creatinine ratio (ACR) more than $30 \mathrm{mg} / \mathrm{g}$ and 30 normotensive patients with T2DM but without albuminuria defined as ACR less than $30 \mathrm{mg} / \mathrm{g} .{ }^{12}$

The exclusion criteria were as follows: (i) Patients with previous history of ischemic heart disease, (ii) Significant chronic kidney disease defined as estimated creatinine clearance below $60 \mathrm{ml} / \mathrm{min} / 1.73 \mathrm{~m}^{2}$, (iii) Atrial flutter or fibrillation or frequent premature ventricular contraction. (iv) Valvular heart disease (significant stenosis or regurgitation of mitral and aortic valves). (v) LV dysfunction with LV EF $<50 \%$. (vi) Resting echocardiography segmental wall motion abnormality. (vii) Suboptimal echocardiographic image quality. 


\section{Anthropometric measurements:}

Body mass index (BMI) and Body surface area (BSA) were calculated for all included individuals where BMI was estimated by measuring weight in kilograms on a balance scale; the height was recorded in meters: $\mathrm{BMI}=$ Weight $(\mathrm{kg}) /$ Height $(\mathrm{m})^{2}$ while (BSA) was measured using Mosteller formula as the square root of product of the weight in $\mathrm{kg}$ times the height in $\mathrm{cm}$ divided by $3600 .{ }^{13}$

\section{Laboratory investigations}

Urine analysis was done to calculate ACR. Other laboratory investigations included $\mathrm{HbA} 1 \mathrm{C}$ and serum creatinine in addition to calculation of estimated creatinine clearance by Cockcroft-Gault formula. ${ }^{14}$

Standard trans-thoracic echocardiographic study:

All individuals were studied in the left lateral decubitus using an ultrasound system Vivid E9 General Electric machine (GE Vingmed Ultrasound AS, Horten, Norway) with an M4S matrix sector array probe with a frequency of 2.5 Mega Hz. Standard 2D, M-mode and Doppler echocardiograms were obtained according to the American Society of Echocardiography guidelines. ${ }^{15,16}$ Basic measurements included LV wall thickness, LV internal dimensions, indexed LV end-diastolic and end-systolic volumes, LV mass index (LVMI) using the Devereux formula and LVEF that was estimated by M mode and modified Simpson's rule. Deceleration time and E/A ratio were measured by pulsed wave Doppler and $\mathrm{E} / \mathrm{E}^{\prime}$ by tissue 
Doppler imaging to assess LV diastolic function as recommended. Left atrial (LA) anterior-posterior dimensions, indexed left atrial end-diastolic and end-systolic volumes were obtained to assess left atrial (LA) function. All echocardiographic examinations as well as follow-up measurements were done by a senior echocardiographer with 10 years' experience in performing echocardiograms.

\section{D strain and strain rate imaging:}

2D echocardiography images were obtained from LV apical long axis, apical four- and two-chamber views by another echocardiographer blinded to the data obtained by the echocardiographer performing the standard transthoracic echocardiographic examination. All images were obtained during breath hold, and stored in cine-loop format from three consecutive beats. The frame rate for images was between 50 and 90 frames/s. All data were transferred to a workstation for further offline analysis.

After defining the endocardial border manually and adjusting the ROI width, an epicardial tracing was automatically developed by the software system in the following sequence: apical long axis, apical four-chamber, and apical two-chamber for LV. For each view, the endocardial border was manually traced in the end-systolic frame.

The software then automatically generated myocardial strain curves by frame-by-frame tracking of the natural acoustic markers throughout the cardiac cycle. If the automatically obtained tracking segments were 
adequate for analysis, the software system was allowed to read the data, whereas analytically inadequate tracking segments were either corrected manually or excluded from the analysis.

The myocardium of the LV was automatically divided into six walls, all walls were then subdivided into three segments (apical, mid, and basal). The longitudinal peak systolic strain was calculated for each segment and the GLS for each view, and average GLS was generated automatically by software and bull's eye was generated for whole LV at the end of analysis (Figure 1). ${ }^{17-19}$

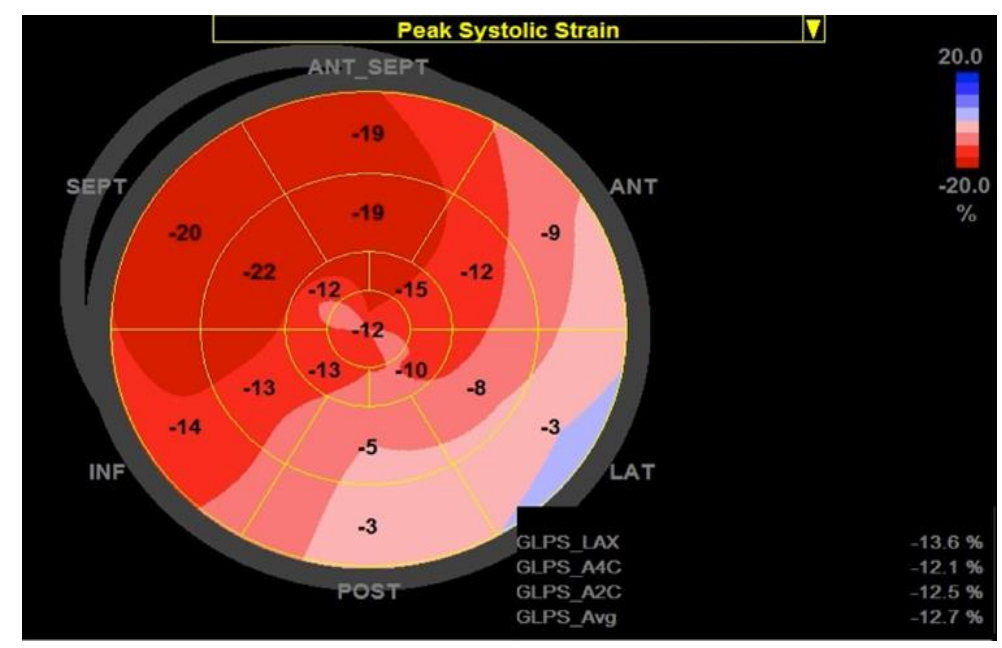

Figure (1): Bull's eye view showing average peak systolic GLS in one of the study group patients

For the purpose of determining the inter- and intra-observer variability, a substudy including 20 patients was conducted where the operator measuring the $2 \mathrm{D}$ strain measured the regional and global strain values twice while the operator responsible for the standard transthoracic 
echocardiographic examination measured the regional and global strain for the same set of patients.

\section{Statistical analysis}

All data were gathered, tabulated, and statistically analysed on a PC using a commercially available statistical software package MedCalc version 11.6.1.0 (MedCalc Software, Mariakerke, Belgium). Qualitative variables were expressed as frequency and percentage. Quantitative variables were expressed as mean $\pm \mathrm{SD}$. Qualitative variables were compared using Chisquared test. Quantitative variables were assessed using paired $t$-test or one-way ANOVA test (if more than two groups). ACR values deviated strongly from a (log) normal distribution (based on skewness/kurtosis) and the median and interquartile ranges (IQRs) were reported and subsequently analyzed by performing non-parametric tests (Mann-Whitney U test and Kruskal Wallis test if more than two groups). Correlations were performed with linear regression and Pearson's coefficient. Correlation coefficient and intra-class correlation were applied for the substudy to assess inter- and intra-observer variability. $P<0.05$ was considered significant, and $P<$ 0.01 was considered highly significant. 


\section{$\underline{\text { Results }}$}

Out of 155 asymptomatic normotensive patients with T2DM recruited from the outpatient clinic, 60 patients were enrolled in this study. Twenty eight patients were accidentally discovered to have significant chronic kidney disease and were ruled out, the remaining 67 patients were excluded from the study due to presence of comorbidities that might affect the LV GLS values as atrial fibrillation $(\mathrm{n}=11)$, asymptomatic valvular heart disease $(n=16)$, resting wall motion abnormality $(n=14)$, Of the excluded patients, 10 had concomitant LV dysfunction defined as EF $<50 \%$ while the rest had poor echocardiographic image quality.

The mean age of the patients was $47.27 \pm 8.47$ years with almost equal sex distribution (males $=31$ versus females 29$)$ that was matching with control group but significantly higher in BMI ( $31.82 \pm 6 . .78$ versus $26.13 \pm 2.99$, $\mathrm{P}<0.001$ ). While $\mathrm{HbA} 1 \mathrm{C}$ and ACR were significantly higher in the study group, the estimated creatinine clearance was significantly lower in the study group $\left(106.8 \pm 30.7 \mathrm{ml} / \mathrm{min} / 1.73 \mathrm{~m}^{2}\right.$ versus $132.3 \pm 30.7 \mathrm{ml} / \mathrm{min} / 1.73$ $\mathrm{m}^{2}, \mathrm{P}=0.01$ ) when compared to control group as shown in table 1 . 
Table (1): Characteristics of study group (patients with T2DM) and control group

\begin{tabular}{|c|c|c|c|}
\hline Variables & Study group (60) & $\begin{array}{c}\text { Control } \\
\text { group (30) }\end{array}$ & P-value \\
\hline Age, years & $47.27 \pm 8.47$ & $46.87 \pm 8.36$ & 0.832 \\
\hline Male, \% & $31(51.7 \%)$ & $19(63.3 \%)$ & 0.294 \\
\hline BMI, kg/m ${ }^{2}$ & $31.82 \pm 6.78$ & $26.13 \pm 2.99$ & $<0.001$ \\
\hline HBA1C, \% & $6.75 \pm 1.14$ & $5.26 \pm 0.46$ & $<0.001$ \\
\hline ACR, median (IQR), $\mathrm{mg} / \mathrm{g}$ & $34.5(11.5-191.5)$ & $4.5(2-8)$ & $<0.001$ \\
\hline Creatinine clearance, $\mathrm{ml} / \mathrm{min} / 1.73 \mathrm{~m}^{2}$ & $106.8 \pm 30.7$ & $132.3 \pm 30.7$ & 0.01 \\
\hline
\end{tabular}

Comparing the results of both diabetic subgroups and the control group all together, there was no favourable results for the non albuminuric group over the albuminuric diabetics for proper diabetes control as expressed by HBA1C values $(6.56 \pm 0.92$ versus $6.93 \pm 1.31, \mathrm{P}=0.147) . \quad$ As regards ACR, the diabetic non-albuminuric sub-group, despite having normal values for ACR, it was significantly higher than the control group (median ACR $11.5 \mathrm{mg} / \mathrm{g}$ versus $4.5, \mathrm{mg} / \mathrm{g} \mathrm{P}<0.001$ ) while on the other hand it was significantly lower than albuminuric subgroup (median ACR $11.5 \mathrm{mg} / \mathrm{g}$ versus $191.5 \mathrm{mg} / \mathrm{g}, \mathrm{P}<0.001$ ) despite exhibiting similar creatinine clearance as shown in table 2. 
Table (2): Characteristics diabetic sub-groups and control group

\begin{tabular}{|c|c|c|c|c|c|c|c|}
\hline \multirow[t]{2}{*}{ Variables } & \multirow{2}{*}{$\begin{array}{c}\begin{array}{c}\text { Albuminuric } \\
\text { subgroup }\end{array} \\
\text { No. }=30\end{array}$} & \multirow{2}{*}{\begin{tabular}{|c|}
$\begin{array}{c}\text { Non- } \\
\text { albuminuric } \\
\text { subgroup }\end{array}$ \\
No. $=\mathbf{3 0}$
\end{tabular}} & \multirow{2}{*}{\begin{tabular}{|c|}
$\begin{array}{c}\text { Control } \\
\text { group }\end{array}$ \\
No. $=\mathbf{3 0}$
\end{tabular}} & \multirow[t]{2}{*}{ P-value } & \multicolumn{3}{|c|}{$\begin{array}{l}\text { Post Hoc } \\
\text { analysis } \\
\text { by LSD }\end{array}$} \\
\hline & & & & & P1 & $\mathbf{P 2}$ & $\mathbf{P 3}$ \\
\hline Age, years & $45.13 \pm 9.13$ & $49.40 \pm 7.28$ & $46.87 \pm 8.36$ & 0.140 & 0.05 & 0.420 & 0.240 \\
\hline Male, \% & $18(60.0 \%)$ & $13(43.3 \%)$ & $19(63.3 \%)$ & 0.248 & 0.196 & 0.790 & 0.120 \\
\hline $\mathrm{BMI}, \mathrm{kg} / \mathrm{m}^{2}$ & $32.78 \pm 7.90$ & $30.86 \pm 5.41$ & $26.13 \pm 2.99$ & 0.000 & 0.204 & $<0.001$ & 0.002 \\
\hline HBA1C, \% & $6.93 \pm 1.31$ & $6.56 \pm 0.92$ & $5.26 \pm 0.46$ & $<0.001$ & 0.147 & $<0.001$ & $<0.001$ \\
\hline $\begin{array}{c}\text { ACR, } \\
\text { Median } \\
\text { (IQR) } \\
\text {,mg/g }\end{array}$ & $191.5(89-280)$ & $11.5(8-15)$ & $4.5(2-8)$ & $<0.001$ & $<0.001$ & $<0.001$ & $<0.001$ \\
\hline $\begin{array}{c}\text { Creatinine } \\
\text { clearance, } \\
\mathrm{ml} / \mathrm{min} / 1.73 \\
\mathrm{~m}^{2}\end{array}$ & $106.3 \pm 31.1$ & $107.3 \pm 30.4$ & $132.3 \pm 30.7$ & 0.002 & 0.9 & 0.0019 & 0.0025 \\
\hline
\end{tabular}

P1: P-value Group 1 versus Group 2, P2: P-value Group 1 versus Control group, P3: P-value Group 2 versus Control group

Regarding echocardiographic 2D findings, the diabetic group had significantly larger LV indexed volumes (both LVEDVI and LVESVI) and same for indexed LA volumes. In addition, the diabetic group had significantly higher LV wall thickness and indexed LV mass. Regarding LV diastolic parameters, the diabetic group showed much more 
deteriorated diastolic functions revealed by significantly higher deceleration time (DT) and E/E' with significantly lower E/A and lateral E' values as shown in table 3 .

Although the standard echocardiographic evaluation for LV systolic function (LVEF) revealed no significant difference between both diabetic and control groups $(\mathrm{P}=0.22)$, all the deformation mechanics measurements GLS (4-ch, 2-ch, LAX and average) were significantly lower in the diabetic group compared to the control group expressing and proving subtle LV dysfunction in diabetics group as shown in table 3 and illustrated in figure 2. 
Table (3): Echocardiographic findings in diabetic patients and control group

\begin{tabular}{|c|c|c|c|}
\hline \multirow{2}{*}{ Echocardiographic variables } & Diabetic Patients & Control group & \multirow{2}{*}{ P-value } \\
\hline & No. $=60$ & No. $=30$ & \\
\hline \multicolumn{4}{|c|}{ Structural measures } \\
\hline LVEDD, mm & $50.82 \pm 4.49$ & $48.83 \pm 2.61$ & 0.028 \\
\hline LVESD, mm & $32.88 \pm 3.44$ & $31.87 \pm 2.21$ & 0.145 \\
\hline IVS, mm & $10.18 \pm 1.35$ & $8.67 \pm 1.32$ & $<0.001$ \\
\hline PWT, mm & $10.10 \pm 1.20$ & $8.87 \pm 1.01$ & $<0.001$ \\
\hline LVEDV index, $\mathrm{ml} / \mathrm{m}^{2}$ & $49.2 \pm 13.9$ & $43.2 \pm 9.1$ & 0.032 \\
\hline LVESV index, $\mathrm{ml} / \mathrm{m}^{2}$ & $17.7 \pm 7.33$ & $16.5 \pm 3.02$ & 0.001 \\
\hline LA volume index, $\mathrm{ml} / \mathrm{m}^{2}$ & $23.23 \pm 5.02$ & $20.26 \pm 2.46$ & 0.003 \\
\hline LV mass index, $\mathrm{mg} / \mathrm{m}^{2}$ & $92.97 \pm 20.07$ & $76.47 \pm 13.41$ & $<0.001$ \\
\hline \multicolumn{4}{|c|}{ Diastolic measures } \\
\hline DT, ms & $179.35 \pm 41.22$ & $147.97 \pm 25.35$ & $<0.001$ \\
\hline E/A & $1.13 \pm 0.50$ & $1.55 \pm 0.27$ & $<0.001$ \\
\hline Lateral E' & $11.47 \pm 4.02$ & $18.27 \pm 3.60$ & $<0.001$ \\
\hline E/e' & $8.80 \pm 3.87$ & $5.24 \pm 1.17$ & $<0.001$ \\
\hline \multicolumn{4}{|c|}{ Systolic measures } \\
\hline LVEF, \% & $62.78 \pm 5.27$ & $64.10 \pm 3.61$ & 0.222 \\
\hline GLS-LAX, \% & $-16.18 \pm 3.10$ & $-19.07 \pm 3.09$ & $<0.001$ \\
\hline GLS-2ch, \% & $-16.38 \pm 3.05$ & $-18.43 \pm 2.34$ & 0.002 \\
\hline GLS-4ch, \% & $-15.97 \pm 3.45$ & $-18.13 \pm 2.86$ & 0.004 \\
\hline GLS-avg, $\%$ & $-16.18 \pm 2.78$ & $-18.57 \pm 2.46$ & $<0.001$ \\
\hline
\end{tabular}




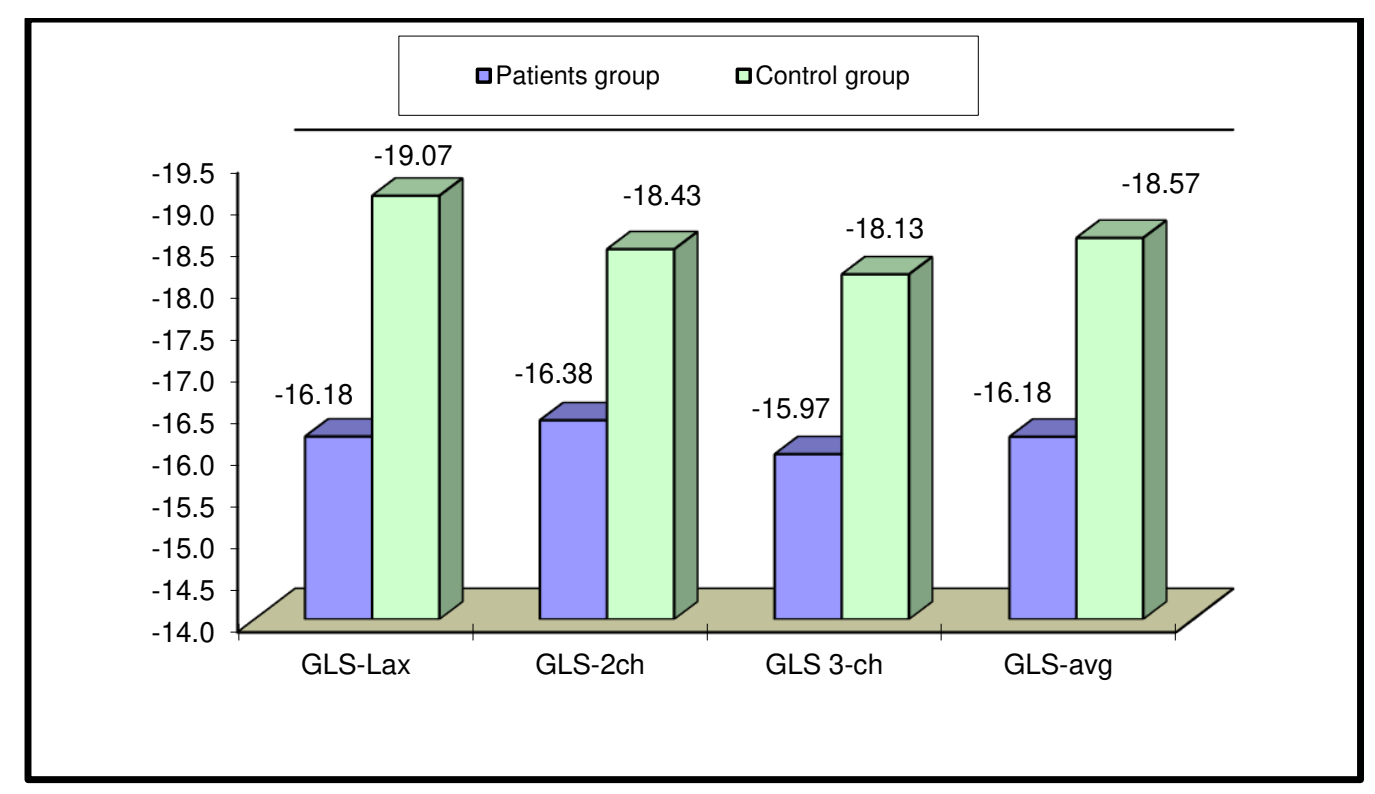

Figure (2): Bar graph shows peak global longitudinal strain in all views in all patient group and control group .

\section{Diabetic subgroups analysis (Albuminuric versus non-albuminuric)}

In spite of being deteriorated in diabetics than control as stated, investigating LV systolic function in both diabetic subgroups didn't show any statistical difference neither in conventional measurements LVEF $(62.20 \pm 5.31 \%$ in diabetic sub-group with albuminuria versus $63.37 \pm$ $5.26 \%$ in diabetic sub-group without albuminuria $\mathrm{P}=0.348$ ) nor in deformation mechanics measurement with mean average GLS $(-15.57 \pm$ $2.77 \%)$ in diabetic sub-group with albuminuria versus $(-16.79 \pm 2.70 \%)$ in diabetic sub-group without albuminuria $(\mathrm{P}=0.077)$, same nonsignificant pattern was recorded in LV diastolic function parameters. The only significant difference between both diabetic subgroups were the indexed LVEDV and LVESV as well as LVEDD being significantly higher in diabetic subgroup with albuminuria as shown in table 4 . 
Table 4: Echocardiographic findings in diabetic sub-groups and control group

\begin{tabular}{|c|c|c|c|c|c|c|c|}
\hline \multirow{2}{*}{$\begin{array}{l}\text { Echocardiographic } \\
\text { data }\end{array}$} & \multirow{2}{*}{$\begin{array}{c}\begin{array}{c}\text { Albuminuric } \\
\text { subgroup }\end{array} \\
\text { No. }=\mathbf{3 0} \\
\end{array}$} & \multirow{2}{*}{\begin{tabular}{|c}
$\begin{array}{c}\text { Non- } \\
\text { albuminuric } \\
\text { subgroup }\end{array}$ \\
No. $=\mathbf{3 0}$ \\
\end{tabular}} & \multirow{2}{*}{\begin{tabular}{|c|}
$\begin{array}{c}\text { Control } \\
\text { group }\end{array}$ \\
No. $=30$ \\
\end{tabular}} & \multirow{2}{*}{$\begin{array}{c}P \text { - } \\
\text { value }\end{array}$} & \multicolumn{3}{|c|}{$\begin{array}{c}\text { Post Hoc analysis } \\
\text { by LSD }\end{array}$} \\
\hline & & & & & P1 & $\mathbf{P 2}$ & $\mathbf{P 3}$ \\
\hline \multicolumn{8}{|c|}{ Structural measurements } \\
\hline LVEDD, mm & $51.97 \pm 4.54$ & $49.67 \pm 4.20$ & $\begin{array}{c}48.83 \pm \\
2.61 \\
\end{array}$ & 0.007 & 0.024 & 0.002 & 0.407 \\
\hline LVESD, mm & $33.33 \pm 2.54$ & $32.43 \pm 4.16$ & $\begin{array}{c}31.87 \pm \\
2.21 \\
\end{array}$ & 0.185 & 0.262 & 0.069 & 0.479 \\
\hline IVS, mm & $10.33 \pm 1.45$ & $10.03 \pm 1.25$ & $\begin{array}{c}8.67 \pm \\
1.32\end{array}$ & $<0.001$ & 0.388 & $<0.001$ & $<0.001$ \\
\hline PWT, mm & $10.23 \pm 1.07$ & $9.97 \pm 1.33$ & $\begin{array}{c}8.87 \pm \\
1.01 \\
\end{array}$ & $<0.001$ & 0.369 & $<0.001$ & $<0.001$ \\
\hline LVEDV index, $\mathrm{ml} / \mathrm{m}^{2}$ & $52.2 \pm 16.3$ & $44.4 \pm 9.7$ & $\begin{array}{c}43.2 \pm \\
9.1 \\
\end{array}$ & 0.002 & 0.001 & 0.03 & 0.062 \\
\hline LVESV index, $\mathrm{ml} / \mathrm{m}^{2}$ & $20.3 \pm 8.7$ & $15.2 \pm 4.4$ & $\begin{array}{c}16.5 \pm \\
3.02\end{array}$ & 0.004 & 0.005 & 0.003 & 0.216 \\
\hline $\begin{array}{l}\text { LA volume index, } \\
\mathrm{ml} / \mathrm{m}^{2}\end{array}$ & $23.05 \pm 4.96$ & $23.40 \pm 5.16$ & \begin{tabular}{|c|}
$20.26 \pm$ \\
2.46 \\
\end{tabular} & 0.012 & 0.757 & 0.015 & 0.007 \\
\hline $\begin{array}{l}\text { LV mass index, } \\
\mathrm{mg} / \mathrm{m}^{2}\end{array}$ & $96.63 \pm 19.01$ & $89.30 \pm 20.75$ & \begin{tabular}{|c|}
$76.47 \pm$ \\
13.41 \\
\end{tabular} & $<0.001$ & 0.118 & $<0.001$ & 0.007 \\
\hline \multicolumn{8}{|c|}{ Diastolic measurements } \\
\hline DT, ms & $177.30 \pm 37.50$ & $\begin{array}{c}181.40 \pm \\
45.19 \\
\end{array}$ & \begin{tabular}{|c|}
$147.97 \pm$ \\
25.35 \\
\end{tabular} & 0.001 & 0.668 & 0.003 & 0.001 \\
\hline E/A & $1.21 \pm 0.53$ & $1.05 \pm 0.46$ & $\begin{array}{c}1.55 \pm \\
0.27\end{array}$ & $<0.001$ & 0.162 & 0.003 & $<0.001$ \\
\hline Lateral E' & $11.63 \pm 3.71$ & $11.30 \pm 4.36$ & \begin{tabular}{|c|}
$18.27 \pm$ \\
3.60 \\
\end{tabular} & $<0.001$ & 0.742 & $<0.001$ & $<0.001$ \\
\hline E/e' & $9.51 \pm 4.15$ & $8.10 \pm 3.50$ & $\begin{array}{c}5.24 \pm \\
1.17\end{array}$ & $<0.001$ & 0.093 & $<0.001$ & 0.001 \\
\hline $\begin{array}{l}\text { LA volume index, } \\
\mathrm{ml} / \mathrm{m}^{2}\end{array}$ & $23.05 \pm 4.96$ & $23.40 \pm 5.16$ & \begin{tabular}{|c|}
$20.26 \pm$ \\
2.46
\end{tabular} & 0.012 & 0.757 & 0.015 & 0.007 \\
\hline \multicolumn{8}{|c|}{ Systolic measurements } \\
\hline LVEF, \% & $62.20 \pm 5.31$ & $63.37 \pm 5.26$ & \begin{tabular}{|c|}
$64.10 \pm$ \\
3.61 \\
\end{tabular} & 0.306 & 0.348 & 0.128 & 0.555 \\
\hline GLS-LAX, \% & $-15.49 \pm 3.11$ & $-16.88 \pm 2.98$ & $\begin{array}{c}-19.07 \pm \\
3.09\end{array}$ & $<0.001$ & 0.081 & $<0.001$ & 0.007 \\
\hline
\end{tabular}




\begin{tabular}{|c|c|c|c|c|c|c|c|}
\hline GLS-2ch, \% & $-15.98 \pm 3.65$ & $-16.78 \pm 2.31$ & $\begin{array}{c}-18.43 \pm \\
2.34\end{array}$ & 0.004 & 0.282 & 0.001 & 0.026 \\
\hline GLS-4ch, \% & $-15.24 \pm 3.11$ & $-16.71 \pm 3.67$ & $\begin{array}{c}-18.13 \pm \\
2.86\end{array}$ & 0.004 & 0.083 & 0.001 & 0.091 \\
\hline GLS-avg, \% & $-15.57 \pm 2.77$ & $-16.79 \pm 2.70$ & $\begin{array}{c}-18.57 \pm \\
2.46\end{array}$ & $<0.001$ & 0.077 & $<0.001$ & 0.011 \\
\hline
\end{tabular}

P1: P-value Group 1 versus Group 2, P2: P-value Group 1 versus Control group, P3: P-value Group 2 versus Control group

\section{Correlation between peak GLS and ACR:}

On studying the correlation between average peak systolic GLS and ACR, it was found that there was a significant reduction in average peak systolic LV GLS with increasing ACR in patients with T2DM $(r=0.38, P=0.003)$ (Figure 3a).Also, there was moderate significant correlation between reduction in average GLS with increasing ACR in patients with T2DM and albuminuria ( $\mathrm{r}=0.55, \mathrm{P}=0.002)$ (Figure $3 \mathrm{~b}$ ). However, this correlation was absent in patients with T2DM without albuminuria $(\mathrm{r}=0.107, \mathrm{P}=0.573)$. 


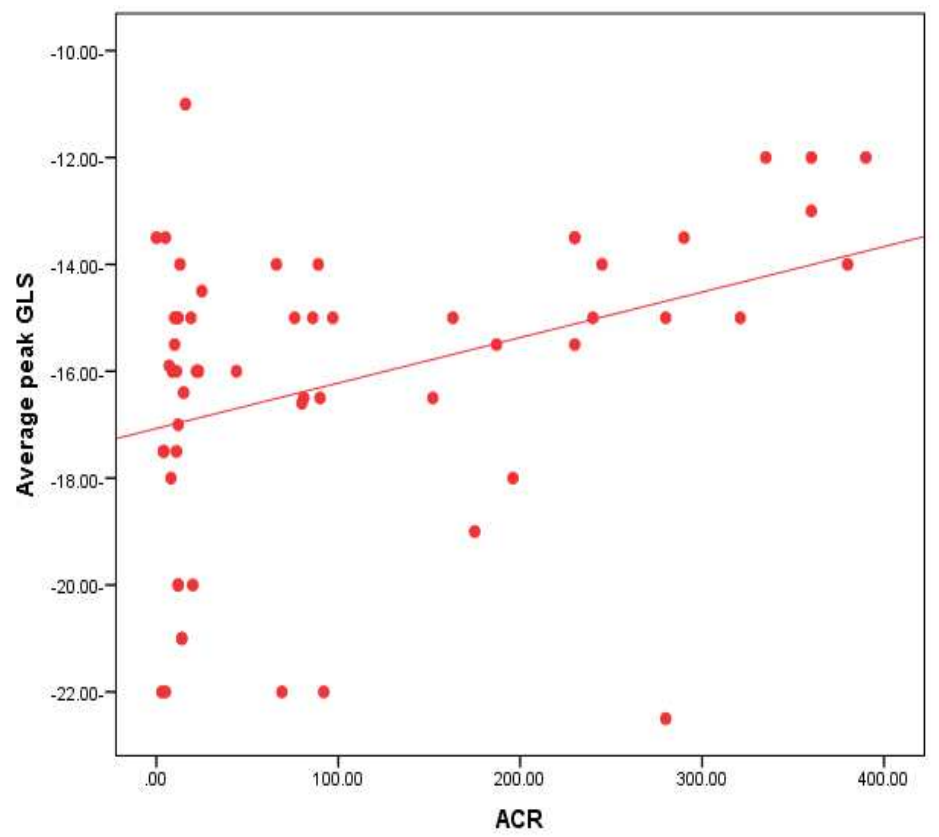

(a)

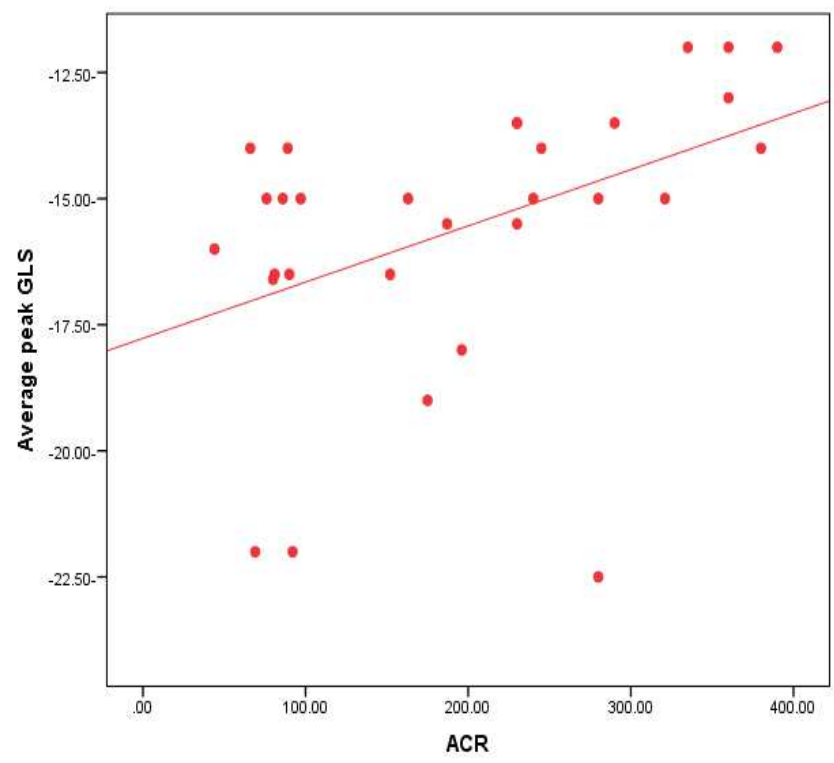

(b)

Figure (3): Correlation between GLS-avg and ACR in the whole diabetic group $(\mathrm{r}=0.38, \mathrm{p}=0.03)$ (a) and in the albuminuric diabetic subgroup $(\mathrm{r}=0.55, \mathrm{p}=0.02)(\mathrm{b})$. 


\section{$\underline{\text { Discussion }}$}

Although CAD is the major cause of death in patients with diabetes mellitus, DCM is increasingly recognized as a clinically relevant distinct entity. In its early stages, DCM includes a hidden subclinical period characterized by structural and functional abnormalities, including LV hypertrophy, fibrosis, and cell signaling abnormalities. These pathophysiological changes of cardiac fibrosis and stiffness and associated subclinical diastolic dysfunction often evolve to heart failure with preserved EF and eventual systolic dysfunction accompanied by heart failure with reduced EF. Therefore, it is important to detect myocardial dysfunction early in T2DM patients using advanced imaging modalities. In this study, echocardiographic evidence of structural cardiac remodeling in T2DM, compared to control group is demonstrated, reflected by statistically significant increment in indexed LV volumes (end-diastolic and end-systolic) and indexed LA volume as well as indexed LVM. LV hypertrophy, which is an ominous prognostic sign and an independent risk factor for cardiac events, is often present in patients with T2DM.

This result agrees with Hirayama et al. who demonstrated in their study that left ventricular mass (LVM) and LVMI were significantly greater in the normotensive patients with T2DM than the normotensive control population. ${ }^{20}$ In addition, this result is concordant with that of Santra et al. who demonstrated that LV hypertrophy is a common association in 
normotensive patients with $\mathrm{T} 2 \mathrm{DM}$ predominantly without micro- or macrovascular complications and hypertension compared to the age- and sex-matched, normotensive non diabetic controls. ${ }^{21}$

However, in the current study, there is no significant difference in LVM index between the nonalbuminuric and albuminuric subgroups. This is discordant with the strong heart study which showed a stepwise increase in prevalence of LV hypertrophy from no albuminuria to macroalbuminuria. This discordance in the results may be attributed to the possible interaction of hypertension in the strong heart study with prevalent hypertension among their study population, , the relatively short duration since initial diagnosis of T2DM in the current study with relatively better glycemic control (lower mean HbA1C) compared to the strong heart study might have contributed to the discordant result. ${ }^{22}$

Not only T2DM is associated with structural remodeling, but it is also associated by functional remodeling in terms of significant changes in all measured diastolic parameters (DT, E/A, lateral E', E/E') denoting significantly increased LV filling pressures. As regards systolic parameters, although LVEF is not significantly different compared to the control group, GLS is significantly reduced. This really adds to the body of published data that speckle tracking use for deformation imaging is more sensitive than LVEF in detecting subtle changes in longitudinal fibers in the subendocardium that are initially affected in the course of DCM, even 
in absence of hypertension and overt CVD. Moreover, GLS has been regarded as a prognostic marker as shown by Liu et al who demonstrated that impaired GLS in T2DM patients with no history of CVD was associated with cardiovascular events and provided incremental prognostic value. $^{23}$

The principal objective of this study was to study the correlation between albuminuria in asymptomatic normotensive T2DM patients and subclinical LV systolic dysfunction. In our study, there is no significant difference in GLS between both subgroups (albuminuric versus non-albuminuric). According to the thousand and one study that compared non cardiac type1 DM (TIDM) patients with non-diabetic healthy control subjects, they found that GLS is reduced in patients with T1DM with albuminuria with no significant difference between control subjects and T1DM patients without albuminuria. ${ }^{24}$ Our study did not show a significant difference in GLS between diabetic patients with or without albuminuria. This may be due to possible difference in pathology between type I and type 2 diabetes mellitus.

Our results disagree with $\underline{\text { Jørgensen }}$ et al, who included patients with T2DM and stratified them according to albuminuria status into no albuminuria, microalbuminuria and macroalbuminuria. Systolic functions were significantly reduced in patients with macroalbuminuria, this 
disagreement between our results may be attributed to smaller number of diabetic patients with macro albuminuria in our study population. ${ }^{25}$

In our study, there is a significant correlation between ACR and reduced average GLS in diabetic patients. In addition, there is a significant correlation between ACR and reduction in average GLS in patients with T2DM and albuminuria $(\mathrm{r}=0.55)$, denoting that once the patients with T2DM commence to develop albuminuria, progressive myocardial involvement ensues that mirrors the degree of albuminuria. This comes in agreement with the thousand and one study, that showed a clear doseresponse relationship between degree of albuminuria and myocardial involvement as patients with macroalbuminuria had lower GLS compared with patients with microalbuminuria. ${ }^{24}$

This finding may give insights into the delicate relationship between microvascular and myocardial involvement in the course of diabetes that denotes their simultaneous progression and intersection together with possible stemming from shared pathophysiological mechanisms. This further reinforces the "common soil hypothesis", where microalbuminuria is regarded as a marker of generalized endothelial dysfunction with perturbed vascular permeability and these changes occur in conjunction with advanced glycation end products, oxidative stress, low grade inflammation, and neovascularization of vasa vasorum can lead to 
macrovascular complications and diabetic cardiomyopathy. ${ }^{26}$ These accumulating data may help not only develop but also understand the effects of novel therapeutic interventions. One obvious example is the new class of anti-diabetic medications (sodium-glucose cotransporter 2 "SGLT2 " inhibitors) with favorable effects on renal and cardiovascular outcomes. A recently published randomized trial in patients with T2DM of empagliflozin versus placebo (EMPA-HEART [Effects of Empagliflozin on Cardiac Structure, Function, and Circulating Biomarkers in Patients With Type 2 Diabetes]) showed that empagliflozin treatment resulted in early and significant reduction in left ventricular mass as detected by cardiac magnetic resonance imaging, which suggests that reverse cardiac remodeling may be a possible contributor to the cardioprotective effects of SGLT-2 inhibitors. $^{27}$ In addition, results from the CREDENCE (Canagliflozin and Renal Events in Diabetes with Established Nephropathy Clinical Evaluation) trial, which investigated canagliflozin versus placebo on renal outcomes in patients with T2DM and albuminuric CKD, support the notion that renal protection and cardiovascular benefit induced by SGLT-2 inhibitors may be interlinked. ${ }^{28}$

\section{Study limitations and recommendations:}

The extensive exclusion criteria applied to the patients before enrolment in the study may suggest that the population is not a real-world population. 
The main objective of this extensive exclusion criteria was to try to document the presence of subtle changes in LV systolic function related to diabetic pathology and not to any other disease process.

Correlation of decreased LV GLS in diabetic population and specially those suffering albuminuria and future development of LV systolic dysfunction defined as $\mathrm{EF}<50 \%$ using longer-term studies should be considered.

This study comprised a few patients with T2DM and macroalbuminuria, thus further study on this patient cohort is recommended.

\section{Conclusions:}

T2DM results in reduction of average peak systolic LV GLS. There is a significant correlation between average peak systolic GLS and ACR in T2DM with albuminuria that may represent the real start of myocardial systolic function decline and thus albuminuria can be used as a marker for risk stratification that identify patients at risk of development of diabetic cardiomyopathy. 


\section{Abbreviations:}

2D: two-dimensional; ACR: albumin creatinine ratio; BMI: body mass index; BSA: Body surface area; HBA1C: glycated hemoglobin; CAD: coronary artery disease; CKD: chronic kidney disease; CVD: Cardiovascular disease; DCM: diabetic cardiomyopathy; DT: deceleration time; SGLT2: sodium glucose co-transporter type 2; GLS: global longitudinal strain; LA: left atrial; LV: left ventricule; LVEDD: left ventricle end diastolic dimension; LVEDV: left ventricle end diastolic volume; LVEDVI: left ventricle end diastolic volume index; LVEF: left ventricular ejection fraction; LVESD: left ventricle end systolic dimension; LVESV: left ventricle end systolic volume; LVESVI: left ventricle end systolic volume index; LVM: left ventricular mass; LVMI: left ventricular mass index; T1DM: type 1 diabetes mellitus; T2DM: type 2 diabetes mellitus.

\section{Authors' contributions}

SR, IB and YA designed the study; NN and IB acquired the data; NN and IB did the data analysis; SR, IB and YA interpreted the data; NN drafted the work and all authors revised it critically for important intellectual content. All authors approved the final version submitted and are accountable for all aspects of the work. All authors read and approved the final manuscript. 


\section{Author details}

${ }^{1}$ Department of Cardiology, Faculty of Medicine, Ain Shams University, Cairo, Egypt.

\section{Acknowledgements}

The authors are grateful for the support of the entire staff of the Department of Cardiology, Ain Shams University Cairo Egypt for the help given during the development of this work and would like to thank the participants and their families for participating in this study.

\section{Competing interests}

The authors declare that they have no competing interests.

\section{Availability of data and materials}

The datasets used and analyzed during the current study are not publicly available due to the individual privacy of the subjects included in this study, but they are available from the corresponding author upon reasonable request.

\section{Consent for publication}

All the authors agree. 
Ethics approval and consent to participate

The study was approved by the ethics committee of the hospital and all participants signed informed consent prior to the study.

\section{Funding}

The authors declare that they have no funding.

\section{$\underline{\text { References }}$}

1. Laing SP, Swerdlow AJ, Carpenter LM, Slater SD, Burden AC, Botha JL, et al. Mortality from cerebrovascular disease in a cohort of 23000 patients with insulin-treated diabetes. Stroke. 2003;34(2):418-21.

2. Jia G, Hill MA, Sowers JR. Diabetic cardiomyopathy: an update of mechanisms contributing to this clinical entity. Circulation research. 2018;122(4):624-38.

3. Miki T, Yuda S, Kouzu H, Miura T. Diabetic cardiomyopathy: pathophysiology and clinical features. Heart failure reviews. 2013;18(2):149-66. 
4. Heerebeek Lv, Hamdani N, Handoko ML, Falcao-Pires I, Musters RJ, Kupreishvili K, et al. Diastolic Stiffness of the Failing Diabetic Heart. Circulation. 2008;117(1):43-51.

5. Gilca G-E, Stefanescu G, Badulescu O, Tanase D-M, Bararu I, Ciocoiu M. Diabetic cardiomyopathy: current approach and potential diagnostic and therapeutic targets. Journal of diabetes research. 2017;2017.

6. Jia C, Olafsson R, Huang S-w, Kolias TJ, Kim K, Rubin JM, et al. Comparison of 2-D speckle tracking and tissue Doppler imaging in an isolated rabbit heart model. IEEE transactions on ultrasonics, ferroelectrics, and frequency control. 2010;57(11):2491-502.

7. Perk G, Tunick PA, Kronzon I. Non-Doppler two-dimensional strain imaging by echocardiography-from technical considerations to clinical applications. Journal of the American Society of Echocardiography. 2007;20(3):234-43.

8. Modesto K, Sengupta PP. Myocardial mechanics in cardiomyopathies. Progress in cardiovascular diseases. 2014;57(1):111-24.

9. Stanton T, Leano R, Marwick TH. Prediction of all-cause mortality from global longitudinal speckle strain: comparison with ejection fraction and wall motion scoring. Circulation: Cardiovascular Imaging. 2009;2(5):356-64. 
10. Miura M, Shiba N, Nochioka K, Takada T, Takahashi J, Kohno H, et al. Urinary albumin excretion in heart failure with preserved ejection fraction: an interim analysis of the CHART 2 study. European journal of heart failure. 2012;14(4):367-76.

11. Gerstein HC, Mann JF, Yi Q, Zinman B, Dinneen SF, Hoogwerf B, et al. Albuminuria and risk of cardiovascular events, death, and heart failure in diabetic and nondiabetic individuals. Jama. 2001;286(4):421-6.

12. Blecker S, Matsushita K, Köttgen A, Loehr LR, Bertoni AG, Boulware LE, et al. High-normal albuminuria and risk of heart failure in the community. American journal of kidney diseases. 2011;58(1):47-55.

13. Mosteller R. Simplified calculation of body surface area. N Engl J Med. 1987;317:1098.

14. Cockcroft DW, Gault H. Prediction of creatinine clearance from serum creatinine. Nephron. 1976;16(1):31-41.

15. Nagueh SF, Smiseth OA, Appleton CP, Byrd BF, Dokainish H, Edvardsen $\mathrm{T}$, et al. Recommendations for the evaluation of left ventricular diastolic function by echocardiography: an update from the American Society of Echocardiography and the European Association of Cardiovascular Imaging. European Journal of Echocardiography. 2016;17(12):1321-60. 
16. Lang RM, Bierig M, Devereux RB, Flachskampf FA, Foster E, Pellikka PA, et al. Recommendations for chamber quantification: a report from the American Society of Echocardiography's Guidelines and Standards Committee and the Chamber Quantification Writing Group, developed in conjunction with the European Association of Echocardiography, a branch of the European Society of Cardiology. Journal of the American Society of Echocardiography. 2005;18(12):1440-63.

17. Johnson C, Kuyt K, Oxborough D, Stout M. Practical tips and tricks in measuring strain, strain rate and twist for the left and right ventricles. Echo research and practice. 2019;6(3):R87-R98.

18. Gorcsan J, Tanaka H. Echocardiographic assessment of myocardial strain. Journal of the American College of Cardiology. 2011;58(14):1401-13.

19. Delgado V, Mollema SA, Ypenburg C, Tops LF, van der Wall EE, Schalij MJ, et al. Relation between global left ventricular longitudinal strain assessed with novel automated function imaging and biplane left ventricular ejection fraction in patients with coronary artery disease. Journal of the American Society of Echocardiography. 2008;21(11):1244-50.

20. Hirayama H, Sugano M, Abe N, Yonemochi H, Makino N. Determination of left ventricular mass by echocardiography in 
normotensive diabetic patients. Japanese circulation journal. 2000;64(12):921-4.

21. Santra S, Basu AK, Roychowdhury P, Banerjee R, Singhania P, Singh S, et al. Comparison of left ventricular mass in normotensive type 2 diabetes mellitus patients with that in the nondiabetic population. Journal of cardiovascular disease research. 2011;2(1):50 .

22. Liu JE, Robbins DC, Palmieri V, Bella JN, Roman MJ, Fabsitz R, et al. Association of albuminuria with systolic and diastolic left ventricular dysfunction in type 2 diabetes: the Strong Heart Study. Journal of the American College of Cardiology. 2003;41(11):20228.

23. Liu J-H, Chen Y, Yuen M, Zhen Z, Chan CW-S, Lam KS-L, et al. Incremental prognostic value of global longitudinal strain in patients with type 2 diabetes mellitus. Cardiovascular diabetology. 2016;15(1):22.

24. Jensen MT, Sogaard P, Andersen HU, Bech J, Hansen TF, BieringSørensen T, et al. Global longitudinal strain is not impaired in type 1 diabetes patients without albuminuria: the Thousand \& 1 study. JACC: Cardiovascular Imaging. 2015;8(4):400-10.

25. Jørgensen PG, Biering-Sørensen T, Mogelvang R, Fritz-Hansen T, Vilsbøll T, Rossing P, et al. Presence of micro- and 
macroalbuminuria and the association with cardiac mechanics in patients with type 2 diabetes. European Heart Journal Cardiovascular Imaging. 2017;19(9):1034-41.

26. Brownlee M. The pathobiology of diabetic complications: a unifying mechanism. diabetes. 2005;54(6):1615-25.

27. Verma S, Mazer CD, Yana AT, Mason T, Slabiak A, Bello OO, et al., editors. EMPA-HEART Cardiolink-6 trial: a randomized trial evaluating the effect of empagliflozin on left ventricular structure, function and biomarkers in people with type 2 diabetes (T2D) and coronary heart disease. Circulation; 2018: LIPPINCOTT WILLIAMS \& WILKINS TWO COMMERCE SQ, 2001 MARKET ST, PHILADELPHIA ....

28. Perkovic V, Jardine MJ, Neal B, Bompoint S, Heerspink HJL, Charytan DM, et al. Canagliflozin and Renal Outcomes in Type 2 Diabetes and Nephropathy. New England Journal of Medicine. 2019;380(24):2295-306. 


\section{Figures}

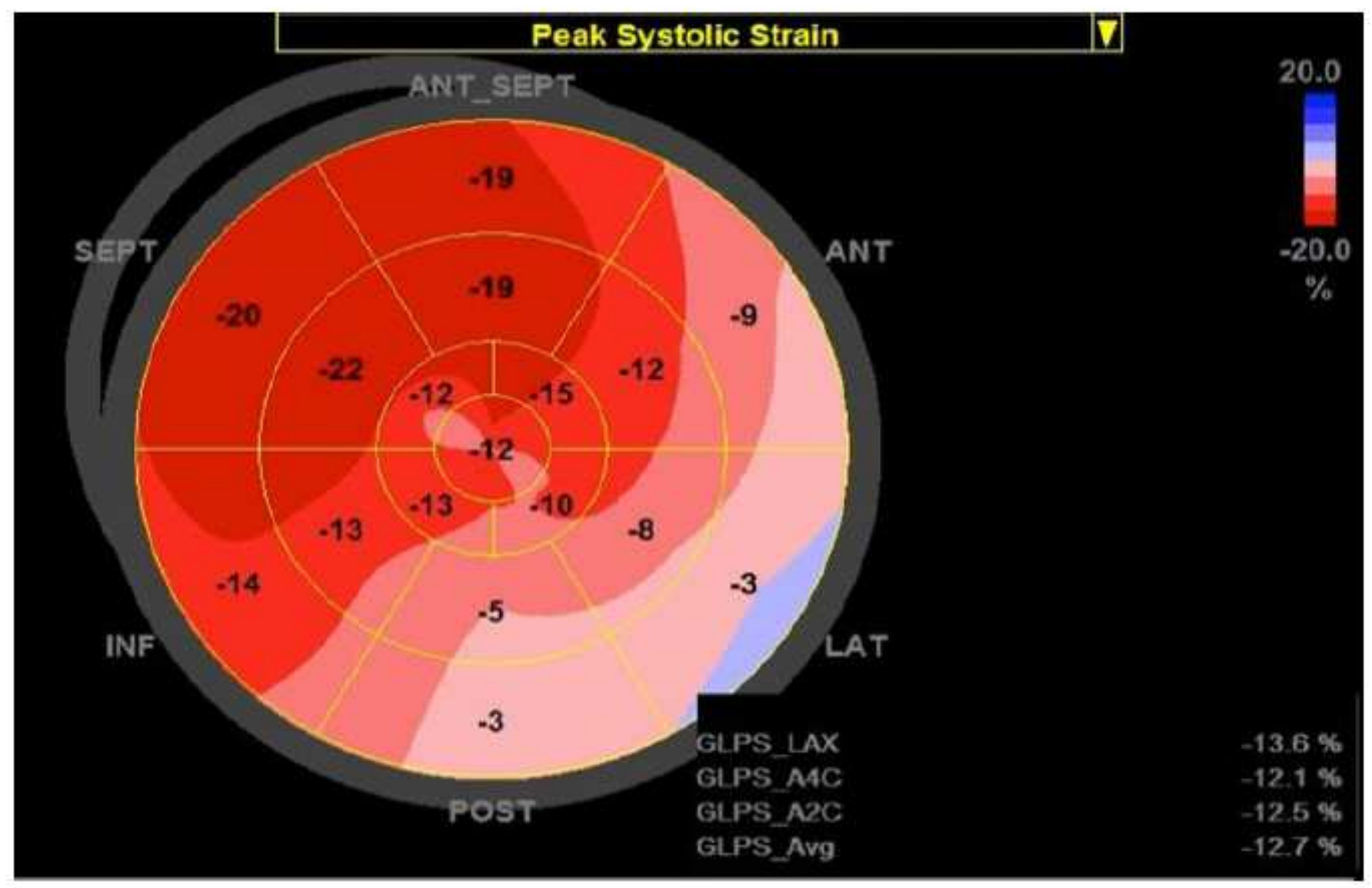

\section{Figure 1}

Bull's eye view showing average peak systolic GLS in one of the study group patients 


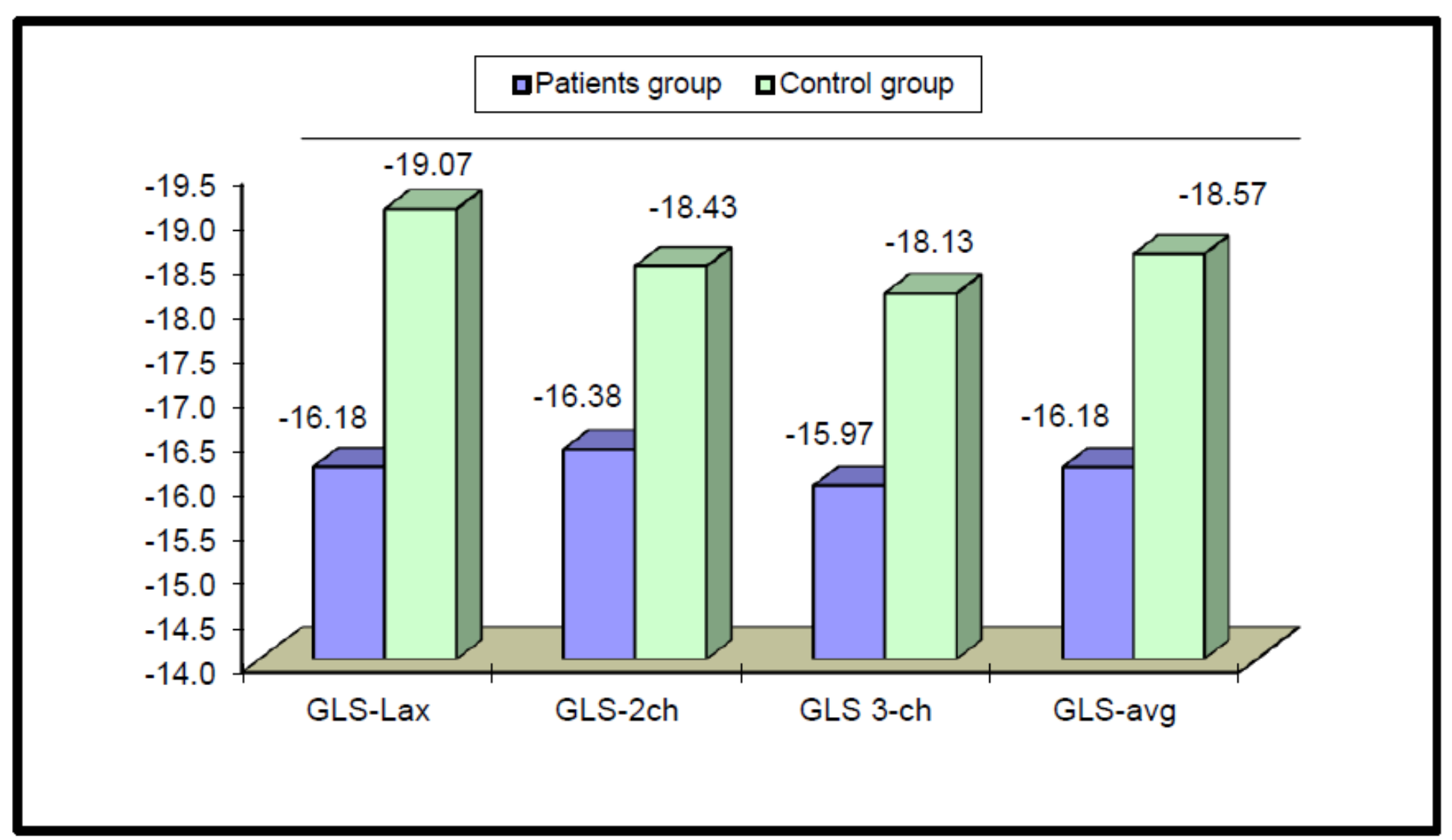

Figure 2

Bar graph shows peak global longitudinal strain in all views in all patient group and control group.

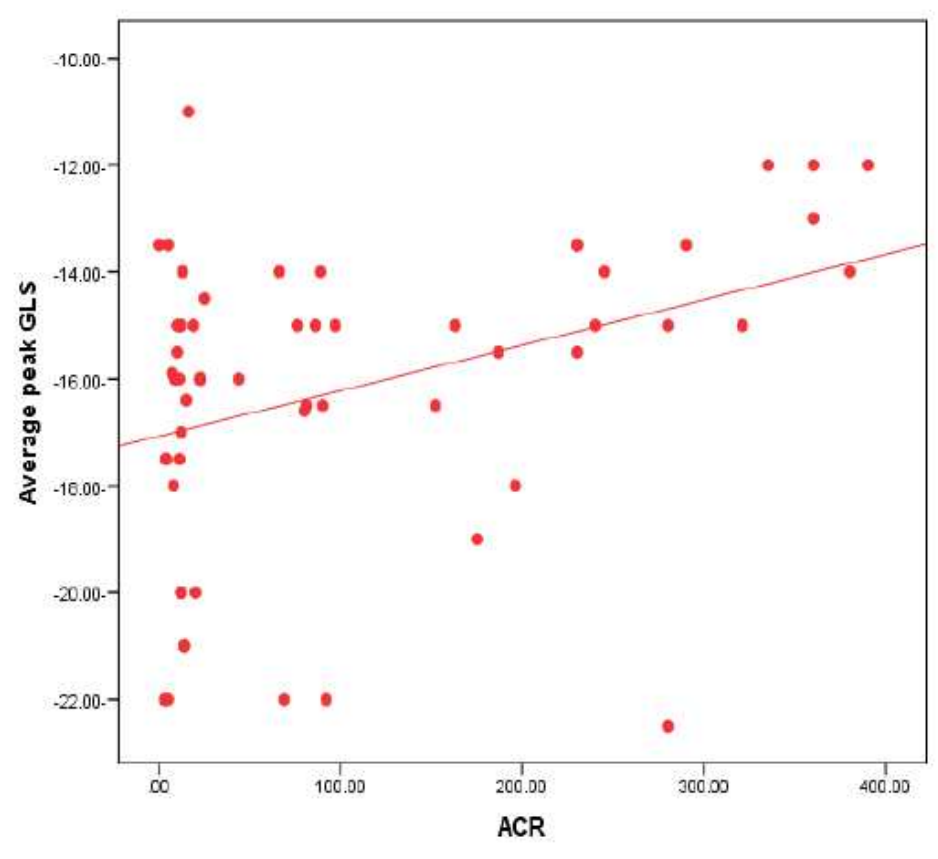

(a)

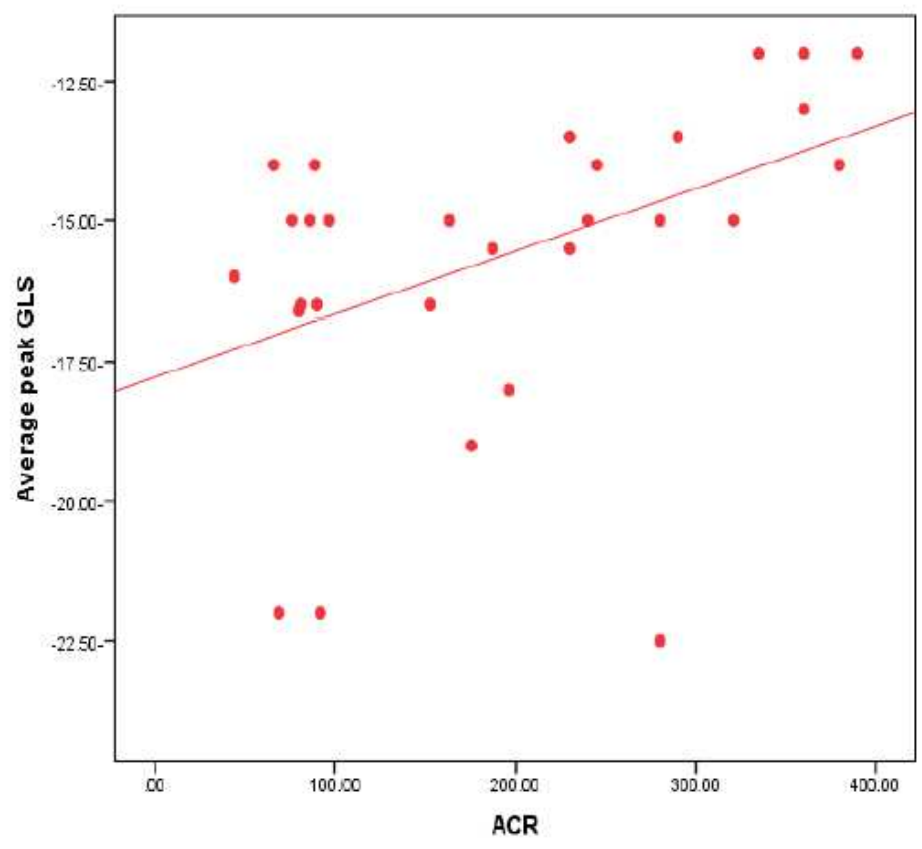

(b)

Figure 3 
Correlation between GLS-avg and ACR in the whole diabetic group ( $r=0.38, p=0.03)(a)$ and in the albuminuric diabetic subgroup $(r=0.55, p=0.02)(b)$.

\section{Supplementary Files}

This is a list of supplementary files associated with this preprint. Click to download.

- TABLES.pdf

- TABLES.pdf

- TABLES.pdf 